\title{
22 Trust is Good - Or is Control Better? Trust and Informal Control in Dutch Neighborhoods - Their Association and Consequences
}

\begin{abstract}
The idea of collective efficacy - the degree to which residents engage in collective good production and protection - has been established as key for the understanding why neighborhoods sometimes fail in establishing social and physical order. Theoretically, a basic assumption is that collective efficacy rests in the close association between informal social control and trust. This paper argues that this alleged link between control and trust is not always present and even not always plausible. Different possible relationships between trust and control are discussed and empirically explored by multilevel models of behavior in neighborhoods, and it is examined to which degree control and trust go with important neighborhood consequences such as networks among neighbors, collective action with neighbors, and general satisfaction with the neighborhood. Data from the SSND (Survey of the Social Networks of the Dutch 2014, $\mathrm{n}=1067$, in 165 neighborhoods) are used. Findings show that trust and informal control are only modestly associated with each other. Furthermore, effects of control are not robust in the statistical models, while trust effects are. Finally, control and trust alignment in different neighborhoods is explored and it is argued that the wider neighborhood context such as type of houses, degree of urbanization and neighborhood history influence the degree to which control goes together with trust.
\end{abstract}

\subsection{Introduction: Collective efficacy and trust-control alignment}

Trust is good, but control is better. ${ }^{1}$

In their seminal paper on the explanation of neighborhood crime and disorder Sampson, Raudenbush, and Earls (1997) argued that collective efficacy is the key for the understanding of how neighbors safeguard collective good production such as

1 This phrase is ascribed to Vladimir Lenin, although there is no source proving that it has been literally forwarded by him. It comes close to a popular Russian saying "Dowjerjaj, no prowjerjaj” which means 'be trusting, but verify'. Probably, Lenin used that saying too.

Beate Volker, Department of Human Geography and Spatial Planning, Utrecht University 
safety, cleanness, and livability of a neighborhood in general. They demonstrated empirically that in neighborhoods where collective efficacy is high, incidents such as registered violence and rates of homicides as well as ratings of perceived violence are lower than in neighborhoods with low collective efficacy. Ever since then, the idea of a lack of collective efficacy - the shared norm that collective goods are protected by interventions of local residents - is used to explain the functioning (or the malfunctioning) of neighborhoods.

The core parts of 'collective efficacy' are social cohesion and perceptions of trustworthiness together with informal control. Collective efficacy is conceived as a composite of trust and informal control, and both are seen as depending on each other. For example, Sampson, Morenoff, and Earls (1999: 919) argue that high trust and cohesion in neighborhoods provides the most "fertile contexts for the realization of informal control". The measurement of collective efficacy is usually straightforwardly based on indicators of trust or cohesion ${ }^{2}$ and combined in one scale, together with items measuring informal control. In most studies on neighborhoods, informal control and trust perceptions are considered to be closely intertwined.

However, the extent to which trust and (informal) control are associated with each other is also debated, in particular in the organizational literature (see for example Bijlsma-Frankema and Costa, 2005; Vlaar, Van den Bosch and Volberda 2007). If trust is understood as the expectation that 'actions of others will be beneficial rather than detrimental' (Gambetta 1988) and control as actively monitoring behavior of others (Janowitz 1991), control and monitoring are not necessary in trustful relationships. On the contrary, in a situation where many trustful relations are present, explicit control can be interpreted as a signal of low trust. ${ }^{3}$ In other words, if control is carried out actively, it can actually be a substitute of trust. In cases where trust is high, control ${ }^{4}$ is not necessary. The opposite also holds: when trust is low, collective good production cannot be warranted without control. Situations where control substitutes trust are quite common and part of rationalization in society. Think for instance of the detailed registrations of employee activities in occupational sectors such as health or education. In fact, control is also an important part of many state

2 In this contribution, the difference between 'trust' and 'social cohesion' is not considered relevant. 'Trust' as used in this chapter refers to dyadic relationships, while 'social cohesion' is a characteristic of a group. However, highly cohesive networks usually consist of trustful and trustworthy relationships and, perhaps more important, most scales on neighborhood cohesion measure trust among neighbors and aggregate the average scores to the level of the neighborhood.

3 I am aware that the situation is more complex, though. On a second level of the interaction, control does play a role. For example, it has to be controlled whether the behavior was indeed in conformation with the agreed norms. Still, however, the argument holds that trust and control cannot be seen as closely related by default.

4 For reasons of brevity I refer to 'control' although my empirical focus as well as my arguments are on 'informal' control. Formal rules and mechanisms are not considered here, since my empirical case, that of neighborhoods lacks these regulations. 
systems as in politics, incentives to abuse power are often large and the consequences of such an abuse undesirable. As Warren (1999) puts it: "An important democratic innovation was the recognition that in many relationships trust is misplaced or inappropriate, suppressing real conflicts of interest" (Warren 1999: 1). In short, the abovementioned Russian saying (footnote 1) has been taken seriously in modern western societies.

However, trust and control can also be related in another way. Control mechanisms can increase trust because the rules of the situation are, with the control mechanisms in place, clear as well as the assessment and evaluation formats. If control is understood as the possibility to sanction (and not as the monitoring of the sanction itself), trust and control are no antagonists anymore. From a game-theoretical perspective, if there is the possibility to sanction (control), in equilibrium, there is no need to carry out the sanction. Hence, in such a situation, control promotes trust (see, for example Coleman 1990, Buskens and Raub 2002). In addition, also for the reversed relationship, that trust promotes control, arguments are provided (see above, Sampson, Moreno and Earls 1999).

Last but not least, it can also be argued that control and trust are two conditions in social situations that operate independently of each other, they might simply be not related in one and the same interaction situation. ${ }^{5}$ Whether control or trust is important for neighborhood social order might depend on the neighborhood matter in question, the organization of a barbeque might be only related to trust in the neighbor networks, while the arrangement on noise, littering, and car parking might be subject to control.

Given these considerations it is actually puzzling that the literature on collective efficacy in neighborhoods does not at all problematize the relationship between control and trust. Instead, it is usually implied that they are equally important and at play at the very same moment. The established conceptualization and the measurement of collective efficacy assume a coincidence of both, trust and control. Hence, while the link between neighborhood disorganization and neighborhood crime is understood in particular through the mediating effect of collective efficacy (Sampson et al. 1999; Sampson 2006), it remains unclear how the constituents of collective efficacy are related to each other. They might be each other's substitute, supplement (and even reinforce each other's effect), or be unrelated.

Knowledge about the relationship between the elements of collective efficacy is important if we want to understand how neighborhoods function and what conditions promote social order. Do people sense and initiate monitoring or do they just trust, without further 'back-up'? Furthermore, does this equally hold for different

5 The situation might be even more complex, though. It might be that in a given situation an initial amount of trust determines the amount of control exercised. 
aspects of neighborhood social order, for instance for actual relationships as well as for actions towards collective good production?

This paper aims to contribute to the disentanglement of the relationship between (informal) control and trust, while studying their consequences for a number of different outcomes: actual neighborhood relations, collective action in neighborhoods, and the general satisfaction with the neighborhood. I focus on the alleged constituents of collective efficacy - trust and control - examine how they are related with each other, and how they contribute to different aspects of neighborhood functioning. In addition, I explore some cases where control and trust are both high, where they are both low, as well as where they do not align. Hence, the research question of this paper is 'what is the association between informal control and trust in neighborhoods, and to what degree do they explain neighbor networks, collective activities, and neighborhood satisfaction?' Data from the 3rd wave of the SSND (Social Survey of the Networks of the Dutch) are used in combination with key-figures of neighborhoods provided by Statistics Netherlands.

\subsection{Collective efficacy, trust, and control - arguments and expectations}

\subsubsection{Collective efficacy}

The idea of collective efficacy and its consequences for a variety of socially desirable outcomes is based on Bandura's psychological theory of individual-level 'personal efficacy' or 'self'-efficacy. This type of efficacy is the belief of individuals that they can attain goals through their own actions - in other words, one's own actions are considered effective for goal attainment (Bandura 1997/2000). Bandura acknowledged that there is also an efficacy belief on a group level: the shared belief in collective power to attain a desired goal. The idea of collective efficacy has been extensively elaborated and applied in sports competitions, but also in educational research (Goddard et al. 2004; Goddard 2001).

In sociology, Sampson, Raudenbush, and Earls (1997) applied the idea of collective efficacy to the study of (dis)functioning neighborhoods, while building upon social disorganization theory. Since the 1970s, social disorganization has been perceived as a community's inability to realize common values and maintain social control (Sampson and Groves 1989; Shaw and McKay 1942). The theory also pointed at three aspects of neighborhood social composition that are expected to enhance disorganization: (ethnic) heterogeneity, residential fluctuation, and disadvantages such as poverty, but also broken families. Consequently, many studies on neighborhood functioning included these three structural neighborhood characteristics in their theoretical and empirical analysis. However, social disorganization theory was 
criticized for being a macro level theory and not connected to human actions (Bursik 1988). What people do in order to establish a well-functioning neighborhood remained an open spot in the theory. Sampson's studies (starting with the abovementioned study by Sampson, Raudenbush and Earls 1997) build upon that criticism of social disorganization theory and argued that the mechanism through which the three compositional characteristics actually work can be found within people's relationships and neighborhood networks. Trust as well as informal control are located in such social networks and they constitute the very base for neighborhood social order. Indeed, both, trust and the shared belief that neighbors will intervene on behalf of the common good - that is, collective efficacy - are associated with low rates of crime, ranging from burglaries to violent offenses and even murder. Sampson et al. (1997) showed that collective efficacy substantially mediates the relationship of cumulated disadvantages, fluctuation, and ethnic heterogeneity in neighborhoods, with neighborhood crime rates and violence acts. Hence, collective efficacy hampers the occurrence of collective bads. ${ }^{6}$

The notion of collective efficacy also met with criticism. It has been questioned whether trust and cohesion are really the constituents of collective efficacy in all circumstances (cf. St. Jean 2007, see also Warner and Rountree 1997). The shared belief that people will intervene on behalf of the common good might be sufficient to enhance neighborhood functioning and the degree to which this shared belief requires trust and cohesive networks can be debated.

In addition, arguments have been brought forward concerning the relationship between trust and control: do they really belong to the same phenomenon? For example, Bursik (1999) argues that social control is an outcome of networks - dense networks produce social control as a collective good and, consequently, in such neighborhoods crime rates are low. However, and as mentioned above, if control is the consequence of trust (or vice versa), research should take into account the chronology in the emergence of trust and control, rather than putting them together in one scale and assume that they are present at the same moment. Last but not least, some researchers showed empirically that the items related to trustful relationships among neighbors did not improve the scale of collective efficacy (see Gau 2014; Volker et al. 2015).

In short, there seem to be inconsistencies in the theoretical arguments on which collective efficacy is based upon as well as in the findings acquired from empirical studies. First, the idea of collective efficacy is explicitly based on trust and control allegedly at play in densely connected, trustful networks. These are networks of stronger ties - and not of weaker ties, given that weaker ties are perceived as less trustful.

6 Volker et al. (2015) showed that collective efficacy also mattered for collective goods: in their study on lost letters in Dutch neighborhoods, letters found in neighborhoods with high collective efficacy were more often returned than the letters found in neighborhoods with low collective efficacy. 
However, it has been shown that strong ties can also hamper control efforts (Bellair and Browning, 2010; Browning, Dietz and Feinberg 2004; Flache 1996) because friends - strong relationships - do not easily take action in case of one's criminal or antisocial behavior. They do not intend to put their relationships at risk. Likewise, it has been shown that dense networks of relationships can hamper collective good production rather than enforce it (Wilson 1996; Morenoff, Sampson and Raudenbush 2001). Second, it has been shown repeatedly that network relationships in a neighborhood are - on average - weak rather than strong (see Volker, Flap and Lindenberg 2006; Marsden 1987), at least when one considers network relationships as the degree of closeness among the interaction partners. Neighbors are not the relationships people talk with about their personal matters and people do not ask their neighbors for advice in important decisions or when they have problems in their relationships. Hence, densely connected networks can have opposite effects than the argument suggests, and the argument does not hold for weakly connected networks - such as the networks commonly found in neighborhoods that are nevertheless functioning quite well. In other words, collective efficacy assumptions might not apply in neighborhoods, nor might they apply in networks of strong ties in general. If that is true, trust and control cannot be the mechanisms that explain neighborhood social order.

\subsubsection{Trust and control}

Although taken for granted in the literature on collective efficacy, the relationship between trust and control is intensely discussed in various fields of the social sciences. In particular the literature on organizational studies and rational choice theory has focused on the connection between trust and control (see Bijlsma-Frankema and Cost, 2005, for an overview). In organizational studies, the relationship between trust and control is studied in relation to governance questions and of growing organizations, with more lateral and less hierarchical relationships. Here, trust and control are often seen as possible antagonists (Deepak and Murnighan 2002) and many authors argue that trust and control are negatively related, (Handy 1993; Ring and Van de Ven 1994; Inkpen and Curral 1997; Cummings and Bromiley 1996; Guseca and Rona-Tas 2001). In that literature, trust is considered as related to risk taking, the risk that one takes while knowing that there is no control that safeguards cooperative behavior. One expects, but cannot be sure, that the actions of other persons are beneficial (Gambetta 1988). Trust and control are considered as substitutes or even negatively related: if one exists, the other is not necessary any more to produce a collective good, or even stronger, one undermines the effect of the other.

While trust can hardly be understood otherwise than as a state of mind, where one has positive expectations towards the actions of others, understanding informal control is more difficult. On the one hand, informal control is a sign of interest and involvement. Think of the teacher, who reads assignments of students and 
comments on them in order to help - while doing this s/he also controls the efforts students have put into the assignment. On the other hand, as already mentioned above, in game theory and rational choice theory, control is understood as the possibility to sanction behavior (cf. Buskens and Raub 2002). In that literature, trust is promoted by control, for instance through sanction possibilities, (but see Mulder et al. 2003). The prominent example is given by Coleman (1988: 98) on the wholesale diamond market, which functions without any written contracts or other guarantees just because of the huge sanction possibilities of the members of the community. Consequently, control (next to learning) is seen as essential for the understanding of trust (see Buskens 1999) and, as argued, control is seen as promoting trust. The idea behind 'control' here takes into account that in many situations there is a short-term incentive to abuse trust, but that this might have undesirable consequences in the future. In situations where the shadow of the future is long and abuse of trust can be sanctioned, individual actions are controlled in the sense that they are remembered and there is a chance of revenge for uncooperative behavior. Reciprocity is conceived as the mechanism underlying this type of control (Blau 1964). Furthermore, the literature on neighborhood and social disorder refers to social control as the "capacity of a group to regulate its members according to desired principles to realize collective [. . .] goals" (Sampson, Raudenbush and Earls, op cit: 918).

Taking together, two perspectives on the relationship between control and trust can be distinguished: the perspective of substitution, and the perspective of supplementation or reinforcement. If one argues from the perspective of substitution, one expects a negative relationship in the sense that high trust does not go together with higher control and vice versa. Even more, trust effects on all kind of outcomes might be weaker in the presence of control. High trust requires only low control and vice versa, in order to secure the collective good (see Dekker 2004; Willamson 1975). Arguing from the perspective of supplementation implies that trust and control are positively related and that the effects of one condition are stronger when the other is present. In other words, trust and control effects reinforce each other. Last but not least, a third perspective can be added: it might depend on the composition of the social setting and on the issue in question how trust and control are related. They both can have independent effects on important outcomes, and the strength of these effects depends on the outcome in question. For example, for feeling safely at night when walking through the neighborhood, it is good to know that neighbors control and monitor what is happening, no matter whether one is trusting anyone. On the other hand, if one has asked his or her neighbors to water the plants during one's holiday, one needs to trust them, whether or not one assumes that they control what is going on in the neighborhood. In summary, I examine three possible relationships between trust and control, that of substitution, of reinforcement and of context dependency. 


\subsubsection{Does it matter? Consequences of collective efficacy}

Collective efficacy has been shown to matter for neighborhood social order. All kinds of incidents such as burglaries or perceived and actual reported violence are lower in neighborhoods where collective efficacy is high (Sampson, Morenoff and Earls 1997, 1999, 2001). In line with the idea of collective efficacy, outcomes for wellbeing and health have also been examined (Sampson 2003; Salanova 2003) - though less often. Mostly, the focus has been on the absence of undesirable outcomes rather than on the presence of desirable ones.

As mentioned, this paper focusses on a number of outcomes that are related to the production of collective goods in neighborhoods. Firstly, and basically, I will consider the number of neighbors in the personal network of residents. Having a vital network in the neighborhood where one lives indicates that one interacts face to face, is present in the neighborhood and possibly involved in all kind of social matters. Secondly, the consequences of trust and control will be examined for collective activities among neighbors. Here I distinguish between (i) social activities such as having coffee together or barbequing in the summer, (ii) activities to keep the neighborhood clean or enhance physical order in the neighborhood, and (iii) activities towards institutions in order maintain neighborhood functioning, such as writing petitions to the municipality etc. Finally, the general satisfaction of residents with their neighborhood is considered as an outcome of collective efficacy trust and control.

These three outcomes indicate behavioral as well as cognitive aspects of how people engage in their neighborhoods. They can be seen as micro-effects of collective efficacy. Studying these different types of outcomes contributes to the understanding of the differential effects of collective efficacy.

\subsubsection{Expectations}

Straightforwardly, trust and control can be related as follows: They might correlate positively - as it is usually assumed - and contribute both to the outcome under consideration. Given the arguments provided above, they might even reinforce each other. Furthermore, they can be substitutes for each other, implying a negative interaction or, at least that a high coefficient in one condition requires only a low coefficient in the other one for the same outcome. In such a case, their relationship will be antagonistic. As argued above, they might also have independent effects, depending on the outcome in question and do not interact. The third perspective is that of context dependency of the relation between trust and control.

This paper is explorative and there are no theoretical arguments derived for the existence of one or the other relationship presented here. However, I do expect that the relation between trust and control is not a universal one but varies among 
neighborhoods and across the outcomes considered. More precisely contextual and compositional neighborhood conditions are expected to matter for the relation between trust and control. For example, in a neighborhood where most residents work full time, building up trustful relationships might be more important than exercising control in case one wants to initiate collective action. Likewise, in a neighborhood with houses built in a way that residents see each other leaving and entering their homes establishing building trust might deserve special attention while control is almost automatically given because of the design of the built environment. Furthermore, it is plausible to expect that the relationship between trust and control is not the same for the phenomena under study: it can be argued that control is more important for collective action - where freeriding behavior is plausible ('if others do it, why should I?') - and that trust is more important for establishing personal relationships or networks in the neighborhood. Neighborhood satisfaction might depend on both control and trust: in a neighborhood where everyone is satisfied people have trustful relationships and those who are not trusted might be controlled.

\subsubsection{A note on reversed causality}

Given the dynamic nature of trust and control (Buskens 1999) as well as the dynamic nature of neighborhood activities, it is obvious that collective efficacy stimulates networks as much as it depends on neighbor interaction. Also, collective actions will enhance collective efficacy, in particular if they are successful, and those who are satisfied with their neighborhood in general probably have higher beliefs of collective efficacy. It has been referred to these phenomena as reciprocal feedback (Sampson and Raudenbush 1999: 630). Here, the scope of my argument is not on these reciprocal relationships, but I consider only one side of the loop: neighborhood outcomes depending on collective efficacy, trust and control, respectively.

\subsection{Data, measurements, and analytical strategy}

Data from the Survey of the Social Network of the Dutch (SSND 2014) were employed for this study. The SSND is a larger research project that started in 1999 and consists of 4 waves of interviews with neighborhood residents. The 2014 wave is the third wave and consists of 1067 respondents of which 578 already participated in 2008 and/or in 1999, and 489 respondents belonged to a refreshment sample in the same neighborhoods plus respondents from a number of newly selected neighborhoods. Neighborhoods were delineated on a 5-position zip code basis, which resulted in 161 relatively small neighborhoods in the sample. Interviewer effects as well as selection in attrition have been examined and indications for neither of 
these have been found. The original sample is a neighborhood sample, drawn from the 545 municipalities in the Netherlands, while taking density of the population in the different regions into account. For more information about the sample and the neighborhood delineation, see, for instance, Volker et al. (2015).

\subsubsection{Dependent variables}

As mentioned above, three kinds of dependent variables have been considered. The number of neighbors in the personal network has been established as follows: networks were delineated based on the exchange method (see Fischer 1987). Respondents were confronted with a relatively large number of name-generating questions, such as whom they ask for help with odd jobs in and around the house, with whom they talk about important matters, work with, whom they visit and the like. In total 11 of such questions have been asked. In every question 5 new persons could be mentioned. This way, a list of names is generated and in a second step information about the characteristics of theses alters as well as of their relationships with the respondent (ego) have been gathered. One of these questions was the role relationship between respondent and network member, of which 'neighbor' was one. Furthermore, because we expected that neighbors are not prominent in many daily activities, we asked whether respondents knew their neighbors. In other words, there were two possibilities for neighbors to enter the network, as a reaction of a name generating question and via a straightforward question after direct neighbors. In this study, both 'types' of neighbors are considered as the number of neighbors in the network.

Activities, collective actions with neighbors have been measured as follows: Respondents have been asked whether they have undertaken one of the following activities with their neighbors during the last few months: social activities, activities towards a more livable neighborhood, and activities towards institutions.

For the measurement of social activities, respondents were asked whether they had i) coffee, ii) a barbeque or a party together. For the measurement of activities towards a better neighborhood they were asked whether they had undertaken activities that made the neighborhood i) more safe, ii) more clean, or ii) whether they had established any rules or arrangement with each other about parking the cars. Lastly, for the measurement of activities towards institutions - the government or the municipality - respondents were asked whether they had undertaken activities like i) calling the police (together), for example because of adolescents hanging around, ii) writing a petition because facilities were removed of the neighborhood or iii) writing a letter of protest to the municipality.

Satisfaction with the neighborhood was measured with the question 'How satisfied are you in general with your neighborhood?' Respondents answered in a 7-point Likert-scale. 


\subsubsection{Independent variables}

Independent variables are informal control and trust in neighborhoods. These have been measured in a similar way as the original items of collective efficacy (Sampson, Raudenbush and Earls, 1997). Neighborhood trust/cohesion was established with the following items:

- people in this neighborhood have good contact with each other,

- if someone needs help, (s)he can count in the neighbors,

- I would not like to have comparable house in another neighborhood, I like it here,

- if there is something to be done, everyone participates,

- I really belong to this neighborhood,

- if I see someone walking in the street I usually know in which house (s)he lives,

- I trust the people in my neighborhood,

- people in this neighborhood trust each other,

- this is a close neighborhood.

Respondents could agree with these items on a 5-point-Likert scale. The items constitute a scale with a Cronbach's alpha of 0.88 .

Informal control is measured as expected interventions, similar as in other scales on collective efficacy. People are asked whether they expect that somebody from the neighborhood would intervene in case

- children hang around skipping lessons

- adolescents spray graffiti

- people in the street have a noisy argument

- they observe an attempt of a burglary

- they observe someone breaking in a car

- children fighting in the street

- the municipality intents to open a center for drug addicted in this neighborhood

- the municipality will take away some benches and a playing ground.

Again, answers could be given in a 5-point-Likertscale. The items constitute a scale with an alpha of 0.89 .

\subsubsection{Control variables}

In all analyses the following individual characteristics were used as controls: sex (women $=0$, men $=1)$, age (on years), country of birth $(0=$ outside of the Netherlands, 
$1=$ Netherlands) and highest education ( 8 categories). In the analyses of the number of neighbors in the network the total network size is also a control variable.

Furthermore, neighborhood composition with regard to age and ethnic background is a control variable. In addition, it is controlled for poverty, a lack of resources and for residential stability: via the percentage of houses for rent, the percentage of divorces, the percentage of people getting unemployment benefit. Urbanization is also controlled for and measured in categories of population density in a squared kilometer. There are 5 classes of urbanism, more than 2500 addresses per km2 (1), between 1500-2500 addresses (2), 1000-1500 addresses (3), 500-100 (4) and less than 500 addresses per km2 (5). All neighborhood control variables were provided by Statistics Netherlands (Statistics Netherlands 2013/2014).

Table 22.1 provides descriptive statistics of key variables in the analyses. Network size is on average 10.7 persons. It can be seen that people differ considerably in their number of neighbors in the network and that the number in general is not high.

Table 22.1: Descriptive statistics of key variables in the analyses.

\begin{tabular}{|c|c|c|c|c|c|c|}
\hline & $\%$ & mean & sd & $\min$ & $\max$ & $\mathbf{N}$ \\
\hline \multicolumn{7}{|l|}{ Individual level control variables } \\
\hline Sex (female) & 50 & & & & & 1069 \\
\hline Age & & 52.9 & 14.3 & 19 & 96 & 1069 \\
\hline Education (1-5) & & & & & & 1068 \\
\hline Only primary school and lower vocational training & 25.1 & & & & & \\
\hline Only secondary school (Mavo, Havo) & 18.2 & & & & & \\
\hline Higher secondary school/vocational training & 22.2 & & & & & \\
\hline Higher vocational training & 21.5 & & & & & \\
\hline University/postgraduation & 13.1 & & & & & \\
\hline Migration background (yes) & 12.9 & & & & & 1069 \\
\hline Network size & & 10.7 & 4.6 & 1 & 29 & 1067 \\
\hline \multicolumn{7}{|l|}{ Dependent variables } \\
\hline $\mathrm{N}$ of neighbors in network & & 2.2 & 1.42 & 0 & 11 & 1067 \\
\hline Social activities with neighbors (count) & & .76 & .79 & 0 & 2 & 1069 \\
\hline Activities to enhance the neighborhood (count) & & .18 & .43 & 0 & 4 & 1069 \\
\hline Political activities (count) & & .45 & .84 & 0 & 2 & 1069 \\
\hline Neighborhood satisfaction (1-7) & & 5.77 & 1.10 & 1 & 7 & 1050 \\
\hline \multicolumn{7}{|l|}{ Independent variables } \\
\hline Cohesion (scale/n of items) & & 3.69 & .61 & 1 & 5 & 994 \\
\hline Informal control expectations (scale/ $\mathrm{n}$ of items) & & 3.93 & .69 & 1 & 5 & 917 \\
\hline \multicolumn{7}{|l|}{ Neighborhood level control variables } \\
\hline$\%$ above 65 years of age & $17 \%$ & & & $2 \%$ & $86 \%$ & 161 \\
\hline$\%$ non-western foreigners & $17 \%$ & & & $0 \%$ & $89 \%$ & 161 \\
\hline$\%$ divorced & $8 \%$ & & & $2 \%$ & $16 \%$ & 161 \\
\hline$\%$ unemployment benefit & $2.5 \%$ & & & $0.8 \%$ & $5 \%$ & 161 \\
\hline$\%$ houses for rent & $46 \%$ & & & & & 161 \\
\hline Degree of urbanism $(1-5,1=$ highest urban areas $)$ & & 2.74 & 1.56 & 1 & 5 & 161 \\
\hline
\end{tabular}


Neighbors make for about $20 \%$ of the network. Furthermore, social activities are highest and activities towards enhancing the neighborhood are relatively rare. Neighborhood satisfaction is high: on average 5.8 out of 7 points.

\subsubsection{Analytical strategy}

The interest in this paper is not the correlation of trust and control within individuals, but within neighborhoods. This means that individual level measures have to be aggregated to the neighborhood. A straightforward procedure of aggregation, such as a sum-score or a multiplication, however, would also aggregate the measurement error and would not take into account that there are differences between measuring individual level characteristics and collective ones. Individual level measurements obviously depend on characteristics of the individual. For example, older people might score systematically higher on trust (which they in fact do) or younger people might systematically rate a neighborhood as not close (which they also in fact do). In these cases, neighborhood composition determines answer patterns which ideally need to be filtered out in order to establish the 'true' level of control and trust. Furthermore, the items that measure control or trust are not independent of each other - just like residents in neighborhoods, these items are nested in respondents. To overcome these obstacles a procedure called 'ecometrics' has been established by Raudenbush and Sampson (1999, see also Mujahid et al. 2007; Raudenbush 2008). Ecometrics broadens the traditional psychometric assessment of individual traits, which usually distinguishes between levels - scale items nested within individuals - by adding a third level, the neighborhood. The goal is to establish a measurement of the aggregated level of the neighborhood. The procedure accounts for individual differences in responses to the given items and for the interdependency of these items. In a first step, a three-level model is estimated: neighborhoods, individuals, and individual level items measuring control and trust, respectively, and it is estimated how the different items contribute to the score on control and trust. Individual scores on neighborhood trust/ control are estimated while controlling for characteristics that determine response patterns such as age, sex, migration background and education into account. Then, the residuals of that measurement, the parts that cannot be attributed to individual response patterns, constitute the measurement of trust/control at the aggregated level and it is used as the independent variable in the final analysis. Reliability (rho) of the ecometric based neighborhood measurements was .71 and .70 for control and trust, respectively. Pearson correlation between the simple aggregation of the values and the ecometric-based measure was .88 (control) and .87 (trust).

The final analyses comprise two levels and two kinds of models. For the number of neighbors in a network and the score for neighborhood satisfaction multilevel regression analyses (Snijders and Bosker 1999) were applied; the analysis for the actions with neighbors was a Poisson regression analysis (since values were 
count data). Negative binomial models were also estimated, and they did not alter the conclusions (not reported here). All analyses started with the estimation of the effect of informal control expectations and then added the indicator of trust to the model. In all models, main effects and interaction effects of cohesion/trust and informal control are estimated.

\subsection{Results}

\subsubsection{Control and trust}

As described in the introduction to this paper, the scale for collective efficacy in the literature by Sampson and colleagues consists of cohesion/trust and informal control expectations. In their study, correlation between the scales for cohesion and control was .80, which justified to collapse them into one new scale, while arguing that the scales obviously were tapping into the same construct (Sampson, Raudenbush, and Earls 1997: 920). However, in the SSND, correlation between both scales is only .51, which is commonly considered to be only a moderate connection. Note that the high correlation between the scales is not always replicated though commonly assumed; see Reisig and Cancino (2004) who suggested that the high correlation is likely to exist in large cities (such as, in their case, Chicago).

\subsubsection{Number of neighbors in network}

Table 22.2 summarizes the multilevel regression estimating number of neighbors in the network.

Table 22.2: Multilevel regression on number of neighbors in network.

\begin{tabular}{|c|c|c|c|c|c|c|c|c|c|}
\hline & \multicolumn{3}{|c|}{ M1 } & \multicolumn{3}{|c|}{ M2 } & \multicolumn{3}{|c|}{ M3 } \\
\hline & Coef. & SE & p & Coef. & SE & p & Coef. & SE & p \\
\hline Informal Control & .105 & .050 & .036 & .036 & .059 & .545 & .029 & .060 & .063 \\
\hline Cohesion & - & - & - & .147 & .058 & .012 & .145 & .058 & .013 \\
\hline $\begin{array}{l}\text { Control*Cohesion } \\
\text { Individual control } \\
\text { variables }\end{array}$ & - & - & - & - & - & - & -.018 & .041 & .655 \\
\hline Sex & -.090 & .043 & .035 & -.094 & .046 & .040 & -.094 & .046 & .040 \\
\hline Age & .313 & .050 & .000 & .322 & .054 & .000 & .321 & .054 & .000 \\
\hline Education & .138 & .049 & .005 & .160 & .053 & .003 & .161 & .053 & .003 \\
\hline Background: native & .018 & .059 & .760 & .030 & .065 & .642 & .029 & .065 & .648 \\
\hline
\end{tabular}


Table 22.2 (continued)

\begin{tabular}{|c|c|c|c|c|c|c|c|c|c|}
\hline & \multicolumn{3}{|c|}{ M1 } & \multicolumn{3}{|c|}{ M2 } & \multicolumn{3}{|c|}{ M3 } \\
\hline & Coef. & SE & p & Coef. & SE & p & Coef. & SE & p \\
\hline $\begin{array}{l}\text { Total network size } \\
\text { Neighborhood } \\
\text { control variables }\end{array}$ & .070 & .010 & .000 & .079 & .011 & .000 & .079 & .011 & .000 \\
\hline $\begin{array}{l}\% \text { above } 65 \text { years of } \\
\text { age }\end{array}$ & -.016 & .058 & .771 & -.034 & .061 & .568 & -.035 & .061 & .560 \\
\hline $\begin{array}{l}\% \text { non-western } \\
\text { foreigners }\end{array}$ & -.040 & .096 & .673 & -.027 & .105 & .795 & -.023 & .106 & .827 \\
\hline $\begin{array}{l}\% \text { on unemployment } \\
\text { benefit }\end{array}$ & .133 & .064 & .038 & .179 & .073 & .016 & .178 & .074 & .016 \\
\hline$\%$ divorced & .070 & .070 & .316 & .076 & .075 & .310 & .078 & .075 & .301 \\
\hline$\%$ houses for rent & -.122 & .085 & .154 & -.118 & .090 & .191 & -.118 & .090 & .190 \\
\hline Population density & .068 & .062 & .274 & .044 & .066 & .504 & .046 & .066 & .049 \\
\hline Intercept & 1.76 & .118 & .000 & 1.71 & .127 & .000 & 1.72 & .127 & .000 \\
\hline Var (cons) & .023 & .039 & & .024 & .044 & & .025 & .044 & \\
\hline Var (res) & 1.320 & .077 & & 1.350 & .083 & & 1.348 & .083 & \\
\hline LL & & 061.75 & & & 168.66 & & & 061.65 & \\
\hline Wald (chi) & 130.96 & .000 & & 125.02 & .000 & 124.96 & .000 & & \\
\hline
\end{tabular}

Note: $\mathrm{n}=973$ respondents in 161 neighborhoods, variables are standardized. ICC $=3.5-4-5 \%$.

Model 1 shows that informal social control is affecting the number of neighbors in the network: more control is associated with larger neighbor networks. Next to this, we found that from the individual level control variables age and education are associated with larger networks in the neighborhood. From the variables on the neighborhood level, a higher percentage of unemployed seems to stimulate many contacts in the neighborhood. Model 2 includes trust in the model and shows that the effect of informal control disappears if cohesion is included. More trust in the neighborhood residents is positively associated with the size of networks in the neighborhood. The interaction term in model 3 is not significant.

\subsubsection{Activities with neighbors}

Tables 22.3a-c summarize the analyses on different types of collective action: social activities, action towards improving the neighborhood and political action. In Table 22.3a we find again that the influence of informal control disappears if trust is added to the model. In addition, the interaction term between control and trust is significant: The association between trust and social activities in the neighborhood is weaker in the presence of control. In Table $22.3 \mathrm{~b}$, concerning the regression on collective action towards neighborhood improvement, both trust and control are significantly related with 
Table 22.3a: Multilevel poisson regression on social activities in neighborhoods.

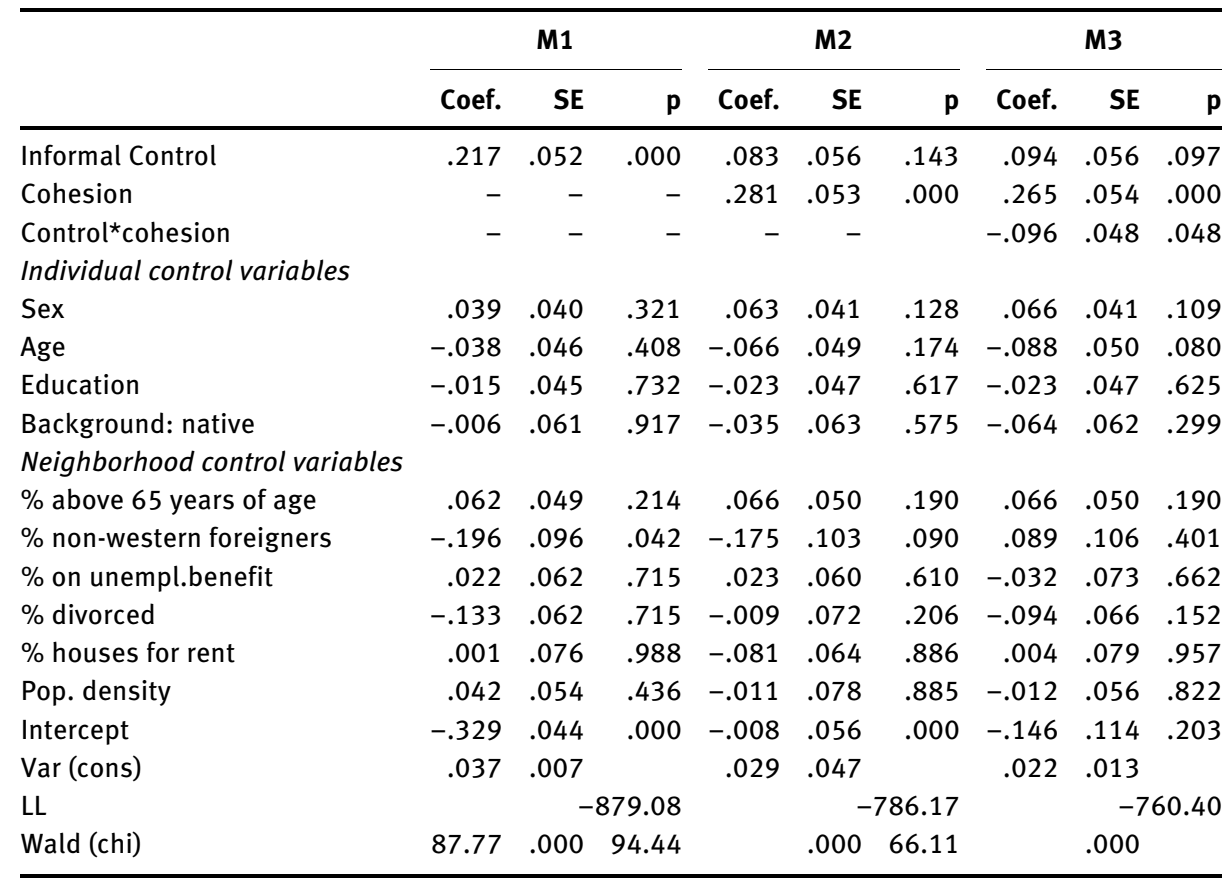

Note: $\mathrm{n}=973$ respondents in 161 neighborhoods, variables are standardized. ICC $=3.5-4-5 \%$.

Table 22.3b: Multilevel poisson regression on neighborhood related collective action.

\begin{tabular}{|c|c|c|c|c|c|c|c|c|c|}
\hline & \multicolumn{3}{|c|}{ M1 } & \multicolumn{3}{|c|}{ M2 } & \multicolumn{3}{|c|}{ M3 } \\
\hline & Coef. & SE & $\mathbf{p}$ & Coef. & SE & $\mathbf{P}$ & Coef. & SE & \\
\hline Informal Control & .284 & .069 & .000 & .183 & .076 & .016 & .171 & .077 & .027 \\
\hline Cohesion & - & - & - & .213 & .073 & .003 & .183 & .074 & .014 \\
\hline Control$^{\star}$ Cohesion & - & - & - & - & - & - & -.045 & .061 & .462 \\
\hline \multicolumn{10}{|l|}{ Individual Control variables } \\
\hline Sex & .077 & .054 & .157 & .065 & .056 & .246 & .089 & .057 & .117 \\
\hline Age & -.006 & .062 & .921 & -.005 & .064 & .927 & -.022 & .067 & .741 \\
\hline Education & .104 & .064 & .106 & .117 & .066 & .076 & .084 & .068 & .217 \\
\hline Background: native & .169 & .093 & .069 & .119 & .093 & .203 & .065 & .093 & .487 \\
\hline \multicolumn{10}{|l|}{ Neighborhood control variables } \\
\hline$\%$ above 65 years of age & .018 & .089 & .838 & .002 & .089 & .978 & .006 & .090 & .944 \\
\hline$\%$ non-western foreigners & .074 & .164 & .650 & .119 & .166 & .473 & .245 & .169 & .148 \\
\hline$\%$ on unemployment benefit & -.061 & .111 & .583 & -.090 & .120 & .450 & -.117 & .121 & .333 \\
\hline$\%$ divorced & .023 & .112 & .837 & .059 & .114 & .602 & .069 & .116 & .055 \\
\hline
\end{tabular}


Table 22.3b (continued)

\begin{tabular}{|c|c|c|c|c|c|c|c|c|c|}
\hline & \multicolumn{3}{|c|}{ M1 } & \multicolumn{3}{|c|}{ M2 } & \multicolumn{3}{|c|}{ M3 } \\
\hline & Coef. & SE & p & Coef. & SE & $\mathbf{P}$ & Coef. & SE & p \\
\hline$\%$ houses for rent & -.016 & .136 & .901 & -.015 & .136 & .912 & -.027 & .138 & .840 \\
\hline Population density & .062 & .102 & .546 & .030 & .103 & .766 & .027 & .105 & .795 \\
\hline Intercept & -1.01 & .089 & .000 & -.919 & .089 & .000 & -1.058 & .176 & .000 \\
\hline $\operatorname{Var}$ (cons) & .391 & .104 & & .365 & .103 & & .382 & .107 & \\
\hline LL & \multicolumn{3}{|c|}{-750.01} & \multicolumn{3}{|c|}{-693.39} & \multicolumn{3}{|c|}{-672.71} \\
\hline Wald (chi) & 33.70 & & & .000 & 33.88 & .007 & .007 & 28.35 & .000 \\
\hline
\end{tabular}

Note: $\mathrm{n}=973$ respondents in 161 neighborhoods, variables are standardized. ICC $=3.5-4-5 \%$.

Table 22.3c: Multilevel poisson regression on political collective action in neighborhoods.

\begin{tabular}{|c|c|c|c|c|c|c|c|c|c|}
\hline & \multicolumn{3}{|c|}{ M1 } & \multicolumn{3}{|c|}{ M2 } & \multicolumn{3}{|c|}{ M3 } \\
\hline & Coef. & SE & $\mathbf{p}$ & Coef. & SE & $\mathbf{p}$ & Coef & SE & $\mathbf{p}$ \\
\hline Informal Control & .255 & .108 & .018 & .125 & .116 & .282 & .159 & .119 & .180 \\
\hline Cohesion & - & - & - & .346 & .108 & .001 & .362 & .112 & .000 \\
\hline Control ${ }^{\star}$ Cohesion & - & - & - & - & - & - & -.192 & .108 & .077 \\
\hline \multicolumn{10}{|l|}{ Individual control variables } \\
\hline Sex & -.020 & .023 & .805 & -.020 & .084 & .807 & -.006 & .084 & .940 \\
\hline Age & .096 & .095 & .312 & .071 & .098 & .469 & .059 & .102 & .561 \\
\hline Education & .201 & .096 & .030 & .217 & .099 & .029 & .212 & .101 & .036 \\
\hline Background: native & .401 & .185 & .038 & .361 & .185 & .051 & .295 & .182 & .105 \\
\hline \multicolumn{10}{|c|}{ Neighborhood control variables } \\
\hline$\%$ above 65 years of age & .136 & .120 & .255 & .049 & .123 & .691 & .046 & .125 & .709 \\
\hline$\%$ non-western foreigners & .107 & .227 & .635 & .097 & .226 & .667 & .222 & .233 & .341 \\
\hline$\%$ on unempl. benefit & .133 & .145 & .359 & .207 & .148 & .164 & .180 & .154 & .240 \\
\hline$\%$ divorced & -.174 & .157 & .264 & -.106 & .158 & .499 & -.110 & .162 & .499 \\
\hline$\%$ houses for rent & .048 & .189 & .799 & .024 & .185 & .897 & .028 & .188 & .879 \\
\hline Pop. density & .167 & .137 & .224 & .134 & .134 & .980 & .132 & .139 & .342 \\
\hline Intercept & -1.95 & .137 & .000 & -1.87 & .135 & .000 & -1.898 & .262 & .000 \\
\hline Var (cons) & .410 & .169 & & .340 & .154 & & .357 & .160 & \\
\hline LL & \multicolumn{3}{|c|}{-415.32} & \multicolumn{3}{|c|}{-396.55} & \multicolumn{3}{|c|}{-760.40} \\
\hline Wald (chi) & 26.61 & & .005 & 32.47 & & .001 & 25.50 & & .003 \\
\hline
\end{tabular}

Note: $\mathrm{n}=973$ respondents in 161 neighborhoods, variables are standardized. ICC $=3.5-4-5 \%$.

the outcome. The coefficient of control decreases, though, once trust is added to the model. There is no interaction effect. Table 22.3c shows, like the models in Table 22.3a, that the coefficient of informal control is not significant anymore in the presence of trust. In addition, the interaction between trust and control is negative: influence of cohesion is weakened by control. 


\subsubsection{Satisfaction with the neighborhood}

Finally, Table 22.4 shows that both informal control and trust contribute to the satisfaction with the neighborhood (see model 2), although the coefficient of control decreases once trust is added to the model. In addition, the interaction between trust and control is found to be negative: the influence of trust is weakened in the presence of control.

Table 22.4: Multilevel regression on neighborhood satisfaction.

\begin{tabular}{|c|c|c|c|c|c|c|c|c|c|}
\hline & \multicolumn{3}{|c|}{ M1 } & \multicolumn{3}{|c|}{ M2 } & \multicolumn{3}{|c|}{ M3 } \\
\hline & Coef. & SE & $\mathbf{p}$ & Coef. & SE & $\mathbf{p}$ & Coef. & SE & $n$ \\
\hline Informal Control & .314 & .035 & .000 & .093 & .033 & .005 & .039 & .032 & .227 \\
\hline Cohesion & - & - & - & .552 & .033 & .000 & .497 & .031 & .000 \\
\hline Control ${ }^{\star}$ Cohesion & - & - & - & - & - & - & -.139 & .022 & .000 \\
\hline \multicolumn{10}{|l|}{ Individual control variables } \\
\hline Sex & -.054 & .031 & .083 & -.020 & .026 & .932 & -.011 & .024 & .635 \\
\hline Age & .068 & .039 & .047 & .002 & .035 & .720 & -.221 & .029 & .456 \\
\hline Education & .069 & .035 & .052 & .052 & .030 & .085 & .049 & .028 & .086 \\
\hline Background: native & .017 & .039 & .658 & .012 & .035 & .720 & -.024 & .035 & .496 \\
\hline \multicolumn{10}{|l|}{ Neighborhood control variables } \\
\hline$\%$ above 65 years of age & .042 & .046 & .362 & -.001 & .037 & .974 & .017 & .033 & .598 \\
\hline$\%$ non-western foreigners & -.376 & .074 & .000 & -.318 & .061 & .000 & -.239 & .057 & .000 \\
\hline$\%$ on unemployment benefit & .090 & .049 & .068 & .117 & .043 & .007 & .063 & .040 & .116 \\
\hline$\%$ divorced & -.093 & .056 & .100 & -.025 & .045 & .581 & -.013 & .041 & .738 \\
\hline$\%$ houses for rent & .043 & .068 & .524 & .047 & .045 & .387 & .051 & .049 & .293 \\
\hline Population density & -.091 & .056 & .074 & -.154 & .041 & .000 & -.140 & .036 & .000 \\
\hline Intercept & 5.795 & .037 & .000 & 5.866 & .030 & .000 & 5.936 & .069 & .000 \\
\hline Var (cons) & .062 & .024 & & .025 & .016 & & .008 & .012 & \\
\hline Var (res) & .716 & .039 & & & & & .395 & .025 & \\
\hline $\mathrm{LL}$ & \multicolumn{3}{|c|}{-1043.52} & \multicolumn{3}{|c|}{-766.49} & \multicolumn{3}{|c|}{-648.18} \\
\hline Wald (chi) & 253.16 & & .000 & 589.3 & & .000 & 124.9 & & .000 \\
\hline
\end{tabular}

Note: $n=973$ respondents in 161 neighborhoods, variables are standardized. ICC $=3.5-4-5 \%$.

\subsection{Intermezzo: Neighborhoods where control and trust coincide - or diverge}

In a last step, the neighborhoods that score either high on one characteristic but low on the other or high/low on both are selected and via Google maps pictures are taken to explore and compare these neighborhoods. A low/high score is assigned if a neighborhood scores on control/trust at least one standard deviation lower/higher than the average. In $20 \%$ of the neighborhoods both the score of control as well as 
of trust was relatively low. In 30\% trust was low but control was high and in 15\% the opposite held. In 35\% of the neighborhoods, both trust and control were rated high. These 4 'types' of neighborhoods were examined and compared via google maps. Using this information, together with the information provided by Statistics Netherlands, I inductively searched for neighborhoods that represent their respective type. A typical neighborhood where both trust as well as informal control were found to be high is in small town, St Annaparochie in the Frisian part of the country. St Annaparochie lies close to the city of Leeuwarden and was founded in the 18th century in the course of the draining of the country and creating the polders. Many people who worked in the draining industry lived there and after the draining ended, they stayed in the new village. In addition, although it is very small - it has less than 5000 residents -, the village has good facilities, such as schools, sport centers and shops. An illustration for this neighborhood can be found here (https://ti nyurl.com/y3uwyyhs). ${ }^{7}$ The picture shows a neighborhood with detached singlefamily houses, seemingly built in the same time period, with gardens in front and probably also behind the houses. They look well-maintained and affluent, but at the same time not extraordinary rich. The streets seem quiet and there is much space and a lot of green.

A typical neighborhood where trust and control are both low is found in a street in Heemskerk in the neighborhood 'Oosterwijk', illustrated here (https://tinyurl. com/y2nv77oa). Heemskerk is located in the province North Holland, and belongs to a small municipality. Like St Annaparochie, it has been a rather rural area until in the sixties a rapid industrialization took place and the city became dominated by a big steal fabric (Hoogovens). Oosterwijk is precisely in between two municipalities, Heemskerk and Beverwijk. It is relatively homogeneous in terms of ethnic background - about $15 \%$ of the residents have a migration background. Incomes are relatively low, and the percentage of social housing relatively high. Note that the municipalities Heemskerk and Beverwijk differ in their social policies, which might constitute problems for the inhabitants of Oosterwijk. The picture shows a street with flat buildings, parking lots and a grocery shop. Buildings are probably from the 60 s and there are many parking lots. Again, there is much space in the area, but houses are no single-family houses but flats for multiple households. There are no greenspaces and many of the small balconies are covered with a canvas sail, probably against the sun and heat. Last but not least there are signs of graffiti and there is an abandoned shopping car, probably belonging to the grocery but stalled around the corner.

7 Google maps permits links to street views, but no offline pictures, see the permissions (https://www. google.com/permissions/geoguidelines/) concerning geographic material. Hence, changes made by google may be reflected in the pictures. The advantage however is that the reader can use the links provided and examine the neighborhoods. 
Where do control and trust not go together? A neighborhood were residents perceive high trust but low control has been found in Leiden (https://tinyurl.com/ y5uqfqwa). Leiden is a relatively small town, close to the coast and surrounded by many tulip farms. Many houses are built in the 19th century or earlier, in medieval times. Leiden hosts the oldest and one of the bigger universities of the country, whereas it has only about 120,000 residents. Almost from the beginning, Leiden has been a city with a cleavage between the higher and lower educated and accordingly segregated neighborhoods. The picture shows a small alley, a bystreet typical for the inner city, with small low-rise houses, probably rented by students. The street is in the center of the city and there are backdoors from a shop or a restaurant, small signs of graffiti and not very well-maintained walls. Some windows are blinded, and many bikes are stalled the street is far too small for cars to pass.

Finally, a typical example of a neighborhood where trust is low, but control is high has been found in Den Haag, Mariahoeve, in the neighborhood 'Burgen en Horsten'. The neighborhood is close to 'Marlot', a neighborhood consisting of villa's and luxury apartments. Before its foundation in 1958, a train rode through the quite green area. The first houses that were built back then were small and meant for housing of blue-collar workers. In present days, about 50\% of the residents is non-native and incomes are below the national average. The neighborhood consists in total of about 15,000 residents and is still a comparatively green neighborhood. Houses are often apartments for multiple households, often almost hidden behind trees. The illustration (https://tinyurl.com/yxzjsyqc) shows such a street with well-maintained garden in front of the houses. Windows are small for Dutch standards and the trees and green spaces seem to hide houses and people.

In terms of the traditional neighborhood characteristics, the four neighborhoods do not much differ in income and wealth. Leiden is the most expensive neighborhood; the housing price in the other three is below the national average (250.000 euro in 2019 according to Statistics Netherlands). Also, with the exception of the neighborhood in Leiden (8\%), the percentage of elderly is between 21 and 25\%. In Oosterwijk and Burgen en Horsten the percentage of migrants is relatively high (between 25 and $30 \%$ ), while it is low in the other two neighborhoods (between 1 and 10\%).

This inductive exercise shows that describing the neighborhoods provides and intuitive understanding that the correlation between trust and control is area dependent. Importantly, we need more information and take more conditions into account when studying neighborhoods and their effects. History and embeddedness of the neighborhood itself seem at least as important as composition and wealth. Green spaces can indicate openness and invite for a chat, but they can also hide people and their housings from each other. 


\subsection{Conclusion and discussion}

The analyses of the association of control and trust lead to a number of conclusions. First, control and trust are only moderately correlated in the Netherlands. This is an interesting finding that adds to the few studies that question the association between control and trust. Second, for the prediction of neighborhood functioning on an individual level, such as the number of neighbors in a network, collective actions with neighbors, and general satisfaction with the neighborhood, (perceived) trust is clearly much more important than control. Note that control has been measured as the expectation that residents will intervene and protect collective goods, if necessary. When included in the analysis, control at first seems to have an impact, but once trust is added to the model, effects of control become insignificant in all cases; only in the analysis of neighborhood satisfaction control remained having a (positive) influence. None of the analyses confirmed the idea that control and trust reinforce each other. However, interaction effects between control and trust turned out to be negative in the case of social activities and neighborhood satisfaction, indicating a substitution effect of trust. In the case of neighborhood collective action trust and control both have a positive main effect, so both contribute to actions towards neighborhood collective good production. This outcome is probably most in line with previous studies on collective efficacy.

It is important to note that neighborhood effects in the analyses were smaller than what is commonly found. The intraclass coefficients did not exceed 5\%. This can be due to inappropriate neighborhood delineation but might also indicate that clustering in general is low. It is an important question for more comparative research to explain why the Dutch case seems to be so different from the American one.

When looking at the examples of neighborhoods where trust and control positively and negatively correlate a couple of interesting conclusions can be drawn - although this is material for further investigation, and, thus far, more illustrative or even anecdotical than established knowledge. Hopefully, future research will provide more arguments on this control-trust alignment by digging more systematically and theory driven than I did in this first account. First of all, it seems that trust and control are more likely to correlate positively in rural regions. In the case of St Annaparochie, it is a very small town, with a history of 'pioneering' residents. In the opposite example, in Heemskerk/Oosterwijk, where both control and trust have been found to be low, part of the explanation might be that industrialization has rapidly taken place, but also rural remnants remained. In a city such as Leiden and in a street, where obviously many young and highly educated people live, high trust but low control is reported. It seems that everyone is trusting, but monitoring is low and in situations where things have to be done and arranged, not-participation is not sanctioned. Finally, the case of Mariahoeve (Burgen en Horsten), an area built in the 60s for the working population is a case of a low income neighborhood where trust is not established, although one can 
argue that all ingredients are present: the neighborhood is relatively green and houses are not too close to each other; they are even often detached.

The study has a number of limitations. First, the number of respondents per neighborhood varied between 2 and 24, which limits the reliability of the constructed measurements at the neighborhood level. Second, neighborhood satisfaction was in general quite high (5.8 on a scale from 1-7) and the standard deviation was with 1.1 quite low. Third, as already mentioned, we cannot draw causal conclusions from these analyses; the causality between for instance trust and the number of neighbors in the network can run in both directions (see also Lanfear, Matsueda, and Beach, 2020, for a critical assessment of causality in collective efficacy studies). Fourth, another limitation of this study is that I did not inquire into neighborhood variation in the models, random slopes for neighborhoods were not included.

Despite of these limitations, the study showed that control and trust can operate independently of each other. This finding is in line with earlier empirical (see Reisig and Cancino 2004, Volker et al 2015) as well as theoretical accounts (see Cook, Hardin and Levi 2005) and indicates that more theorizing is needed in order to understand under which conditions control and trust correlate or not. In addition, the series of exemplary photographs showed that neighborhoods - at least in the Netherlands could not be grasped by common dimensions that neighborhood researchers use such as residential fluctuation, poverty, and the number of foreigners. 'Classical' compositional indicators as well as indicators of the built environment seem to tell a limited story. Green spaces can integrate people as well as separate them. A middle-class neighborhood can show low trust and cohesion, although all the ingredients for high trust are present. Likewise, a neighborhood where many students and academics live, can be cohesive and trustful, but nobody would step forward and take action necessary for collective good creation. Future research might gain by focusing more on these empirical anomalies, not yet predicted by established theoretical arguments.

Last but not least, the history of a neighborhood - rapid industrialization, pioneers who drained land from the water, or a newly built neighborhood for people, who are at the lower end of the income ladder, all matter for trust and control. Neighborhoods have a 'memory' - in the sense that people do not move out altogether. They were built with a purpose, which probably keeps influencing neighborhood affairs. As such, knowledge about history and architecture/land-use can help to develop a better understanding of neighborhoods in the Netherlands.

To conclude, in the Netherlands, trust and control in neighborhoods do not go systematically together when explaining neighborhood matters. Outcomes seem more driven by trust and its aggregate, social cohesion, than by informal control. However, the relationship between trust and control in neighborhoods varies a lot and future research has to establish more systematically the contextual conditions under which control and trust align or substitute each other when explaining neighborhood collective action and networks. 


\section{References}

Bandura, Albert. 1997. Self-efficacy: The exercise of control. London, Macmillan Publishers.

Bandura, Albert. 2000. "Exercise of human agency through collective efficacy." Current Directions in Psychological Science, 9, 3, 75-78.

Bellair, Paul, E. and Christopher, R. Browning. 2010 "Contemporary disorganization research: An assessment and further test of the systemic model of neighborhood crime." Journal of Research in Crime and Delinquency, 47(4), 496-521.

Bijlsma-Frankema, Katinka and Ana Cristina Costa. 2005. "Understanding the trust-control nexus." International Sociology, 20, 3:259-282.

Blau, Peter, M. 1964. Exchange and Power in Social Life. New York, John Wiley.

Bursik, Robert, J. 1988. "Social disorganization and theories of crime and delinquency: Problems and prospects." Criminology, 26(4), 519-552.

Bursik, Robert, J. 1999. "The informal control of crime through neighborhood networks." Sociological Focus, 32,1, 85-97.

Buskens, Vincent. 1999. Social Networks and Trust. Amsterdam: Thela Thesis.

Buskens, Vincent, and Werner Raub. 2002. Embedded trust: Control and learning. Advances in Group Processes, 19, 167-202.

Browning, Christopher, R., Robert, D. Dietz, and Seth, L. Feinberg. 2004. "The paradox of social organization: Networks, collective efficacy, and violent crime in urban neighborhoods." Social Forces, 83,2, 503-534.

Coleman, James S. 1988. "Social capital in the creation of human capital." American Journal of Sociology 94: S95-S120.

Coleman, James, S. 1990. Foundations of Social Theory. Boston, Belknap Press.

Cook, Karen, Margaret Levi, and Russel Hardin. 2005. Cooperation without trust? New York, Russell Sage Foundation.

Cummings, Larry L., and Philip Bromiley. 1996. "The organizational trust inventory (OTI)." Trust in organizations: Frontiers of theory and research 302, 330: 39-52.

Dekker, Henri C. 2004. "Control of Inter-Organizational Relationships: Evidence on Appropriation Concerns and Coordination Requirements." Accounting, Organizations, and Society 29, 27-49.

Flache, Andreas. 1996. The double edge of networks: An analysis of the effect of informal networks on cooperation in social dilemmas. Amsterdam: Thesis Publishers.

Gau, Jacinta, M. 2014. "Unpacking collective efficacy: the relationships between social cohesion and informal social control." Criminal Justice Studies 27, 2, 210-225.

Gambetta, Diego.1988. “Can we trust trust?” In: Diego Gambetta (ed.), Trust: Making and Breaking Cooperative Relationships, pp 213-237. Cambridge, MA, Blackwell.

Goddard, Roger D., Wayne K. Hoy, and Anita Wollfolk Hoy. 2004. "Collective efficacy beliefs: Theoretical developments, empirical evidence, and future directions." Educational researcher, 33,3, 3-13.

Goddard, Roger, D. 2001. "Collective efficacy: A neglected construct in the study of schools and student achievement." Journal of Educational Psychology, 93,3, 467.

Guseva, Alya, and Akos Rona-Tas. 2001. "Uncertainty risk and trust: Russian and American credit card markets compared." American Sociological Review, 66: 623-646.

Handy, Charles. 1993. "Understanding Organizations." 4th ed. London, Penguin.

Inkpen, Andrew C., and Currall, Steven C. 1997. "International Joint Venture Trust: An Empirical Examination", in Paul W. Beamish and Peter Killing (eds) Cooperative Strategies: Volume 1. North American Perspectives, pp. 308-34. San Francisco, CA, New Lexington Press. 
Janowitz, Morris. 1991. “On social organization and social control.” Chicago, IL, University of Chicago Press.

Lanfear, Charles C., Ross, L. Matsueda, and Lindsey R. Beach. 2020. "Broken Windows, Informal Social Control, and Crime: Assessing Causality in Empirical Studies." Annual Review of Criminology 3,1 doi.org/10.1146/annurev-criminol-011419-041541 In advance first posted online on October, 7, 2019.

Malhotra, Deepak, and J. Keith Murnighan. 2002. "The effects of contracts on interpersonal trust." Administrative Science Quarterly 47 (3), 534-559.

Marsden, Peter, V. 1987. “Core discussion networks of Americans." American Sociological Review, $52,1,122-131$.

Morenoff, Jeffrey D., Robert J. Sampson, and Stephen, W. Raudenbush. 2001. "Neighborhood inequality, collective efficacy, and the spatial dynamics of urban violence." Criminology, 39, 3, 517-558.

Mujahid, Mahasin S., Ana Diez-Roux, Jeffrey, D. Morenoff, and Trivellore Raghunathan. 2007. "Assessing the Measurement Properties of Neighborhood Scales: From Psychometrics to Ecometrics." American Journal of Epidemiology, 165:858-67.

Mulder, Laetitia, Eric van Dijk, David de Cremer, Henk A.M. Wilke. 2003. "Undermining trust and cooperation: The paradox of sanctioning systems in social dilemmas." Journal of Experimental Psychology, 42, 147-162.

Raudenbush, Stephen. 2008. Many Small Groups. In: Handbook of Multilevel Analysis, edited by Jan DeLeeuw and Erik Meijer, pp. 207-36. New York: Springer.

Raudenbush, Stephen and Robert Sampson. 1999. "Ecometrics: Towards a Science of Assessing Ecological Settings: With Application to the Systematic Social Observation of Neighborhoods." Sociological Methodology 29,1,1-41.

Reisig, Michael, D. and Jeffrey, M. Cancino. 2004. "Incivilities in nonmetropolitan communities: The effects of structural constraints, social conditions, and crime." Journal of Criminal Justice, $32,1,15-29$.

Ring, Peter S., and Andrew. H. Van de Ven. 1994 "Developmental processes of cooperative interorganizational relationships." Academy of Management Review, 19:90-118.

Shaw, Clifford and Henry McKay. 1942. Juvenile Delinquency and Urban Areas. Chicago, IL, University of Chicago Press.

Salanova, Marisa, Susanna Llorens, Eva Cifre, Isabel M. Martínez, and Wilmar B. Schaufeli. 2003. "Perceived collective efficacy, subjective well-being and task performance among electronic work groups: An experimental study." Small Group Research, 34,1, 43-73.

Sampson, Robert, J. and W. Byron Groves. 1989. Community structure and crime: Testing socialdisorganization theory. American Journal of Sociology, 94 (4),774-802.

Sampson, Robert, J. and Stephen W. Raudenbush. 1999. Systematic social observation of public spaces: A new look at social disorder in urban neihghborhoods. American Journal of Sociology, 105, 3, 603-651.

Sampson, Robert J. 2006. "Collective efficacy theory: Lessons learned and directions for future inquiry.” In: Francis T. Cullen, John Paul Wright, Kristie R. Blevins, (eds) Taking Stock: The Status of Criminological Theory 15: 149-67.

Sampson, Robert J., Stephen W. Raudenbush, and Earls, F. 1997. "Neighborhoods and violent crime: A multilevel study of collective efficacy." Science, 277(5328), 918-924.

Sampson, R. J., Jeffrey Morenoff., \& Felton Earls. 1999. "Beyond social capital: Spatial dynamics of collective efficacy for children." American Sociological Review, 64 (5), 633-660.

Sampson, Robert J. 2003. "The neighborhood context of well-being." Perspectives in Biology and Medicine, 46(3), S53-S64. 
Snijders, Tom and Roel Bosker. 1999. Multilevel Analysis: An Introduction to Basic and Advanced Multilevel Modeling. London: Sage.

SSND. 2014. The survey of the social network of the Dutch. Wave 3. Beate Volker and Gerald Mollenhorst. Data and Codebook. Utrecht University.

Statistics Netherlands. 2013/2014. Key Figures of Neighborhoods. The Hague: CBS.

St.Jean, Peter, K. B. 2007. Pockets of Crime: Broken Windows, Collective Efficacy, and the Criminal Point of View. Chicago: University of Chicago Press.

Vlaar, Paul W.L., Frans A.J. Van den Bosch, and Henk, W. Volberda. 2007. "On the evolution or trust, distrust, and formal coordination and control in interorganizational relationships. Towards and integrative framework." Group \& Organization Management, 32, (4), 407-429

Volker, Beate, Henk Flap, and Siegwart Lindenberg. 2007. "When are neighbourhoods communities? Community in Dutch neighbourhoods." European Sociological Review, 23(1), 99-114.

Volker, Beate, Gerald Mollenhorst, Wouter Steenbeek, Veronique Schutjens, and Henk Flap. 2015. "Lost letters in Dutch neighborhoods: A field experiment on collective efficacy." Social Forces, 94,3, 953-974.

Warner, Barbara, D. and Rountree, Pamela, W. 1997. "Local social ties in a community and crime model: Questioning the systemic nature of informal social control.”: Social Problems, 44(4), 520-536.

Warren, Mark E. 1999 (eds). Democracy and Trust. Cambridge: Cambridge University Press.

Williamson, Oliver. E. 1975. Markets and Hierarchies. New York: Free Press.

Wilson, William, J. 1996. When Work Disappears: The World of the New Urban Poor. New York: Alfred Knopf. 
